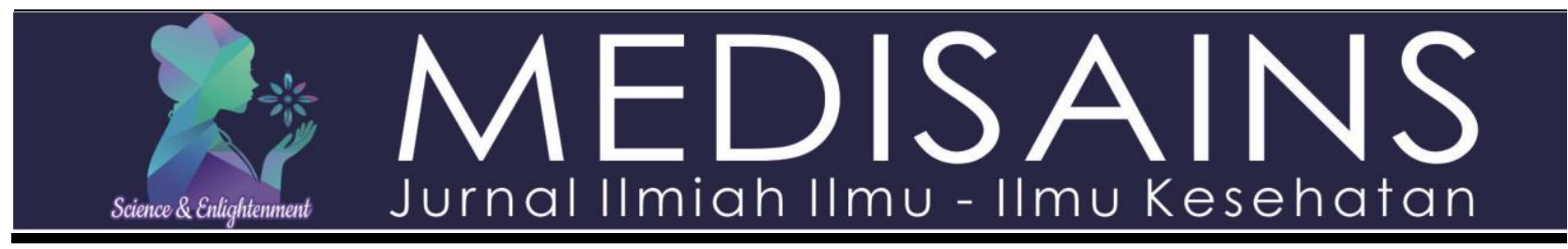

Original Article

\title{
Evaluation of surface modified PLLA-collagen hollow fiber as vascular graft
}

Dita Ayu Mayasari ${ }^{1}$, Prihartini Widiyanti ${ }^{2}$, Djony Izak Rudyardjo ${ }^{3}$

${ }^{1}$ Biomedical Engineering, Faculty of Engineering, Universitas Dian Nuswantoro, Semarang, Indonesia

${ }^{2}$ Biomedical Engineering, Faculty of Science and Technology, Universitas Airlangga, Surabaya, Indonesia

${ }^{3}$ Physics, Faculty of Science and Technology, Universitas Airlangga, Surabaya, Indonesia

\section{ARTICLE INFORMATION}

Received: Agustus 22, 2019

Revised: September 03, 2019

Available online: Oktober 01, 2019

\section{KEYWORDS}

Chitosan; Collagen; Atherosclerosis; Polymers; Coronary Artery Bypass

\section{CORRESPONDENCE}

Phone: +628563257268

E-mail: mayasari.dita@dsn.dinus.ac.id

\section{A B S T R A C T}

Background: Cardiovascular disease as the first silent killer in the world is related to atherosclerosis plaque. Coronary artery bypass grafting as a gold standard for severe atherosclerosis needs alternative materials to replace the narrowed artery due to plaque. PLLA is one of the biodegradable polymers which is suitable for the vascular graft, but some of its weaknesses should be addressed.

Objective: The aim of this research is to improve PLLA characteristics for a vascular graft candidate by using collagen and chitosan.

Methods: This study was an experimental study that consisted of two steps, preparation of hollow fiber and evaluation of its characteristic. This research evaluated the effect of chitosan concentration against cytotoxicity and hemocompatibility using MTT assay and hemolytic test.

Results: The result showed that chitosan could improve the biological characteristics of hollow fiber PLLA-collagen, non-toxic, and non-hemolytic.

Conclusions: There is a good effect on the biological characteristics of PLLACollagen hollow fiber by adding chitosan on the surface of PLLA-Collagen hollow fiber.

\section{INTRODUCTION}

Cardiovascular disease (CVD) is the first silent killer in the world. Though it has been declined in the last 25 years, it is still the first killer ${ }^{1,2}$. It has been predicted that $45 \%$ of the adult population in the US will suffer CVD in $2035{ }^{3}$. CVD is related to coronary atherosclerosis plaque. Atherosclerosis is a condition where the blood vessel get narrow due to plaque ${ }^{4}$. The most common effective treatment for severe atherosclerosis is coronary artery bypass grafting $(\mathrm{CABG})^{5}$. CABG is a gold standard for surgery to replace a narrowed artery with new vessels. The new vessels for CABG usually come from autologous vessels, such as a saphenous vein and internal thoracic artery. Unfortunately, the viability of the source is limited. Moreover, it requires an invasive harvest, and it is often unsuitable for use ${ }^{6,7}$. Due to some limitations for autologous vessels, synthetic vascular graft is needed as an alternative ${ }^{6}$.
The synthetic vascular graft should be made from materials that have good characteristics, such as, hemocompatible, non-toxic, non-thrombogenic, and good mechanical characteristics. Polymer is one of the materials that has been used for the vascular graft. One kind of polymers suitable for the vascular graft is poly L-lactic acid (PLLA). PLLA is a common biodegradable polymer for synthetic vascular graft ${ }^{8}$. The previous research showed that a porous PLLA nanofiber scaffold is very potential for vascular graft tissue engineering reconstruction ${ }^{9}$.

PLLA has degradation times around 6-12 months ${ }^{10}$. It can be accepted on the human body due to the presence of lactic acid. Unfortunately, PLLA is not able to promote cell growth and differentiation. Growth-factor-like substances should be added on PLLA to trigger cell adhesion. The previous study showed that collagen improved the ability of PLLA to promote cell growth and differentiation ${ }^{11}$. 
The degradation product of PLLA is able to enter the Kreb's cycle. The degradation process of PLLA occurs due to the hydrolytic mechanism. It is started from the diffusion process of body fluid to materials and cut the chain off on the oligomer ${ }^{12}$. This hydrolytic degradation causes the decline of $\mathrm{pH}$, so that is triggering inflammation reaction and allergenic ${ }^{13}$. Another drawback of PLLA is its hydrophobic characteristics which do not lead the cell adhesion. Therefore, surface modification is needed to improve the biological characteristics of PLLA ${ }^{14}$.

Chitosan is added on the surface to cover the hydrophobic surface of the PLLA. Chitosan will induce cell proliferation and minimize the odd body reaction. Chitosan is a natural cationic that can act as a buffer to maintain the $\mathrm{pH}$ of PLLA during the degradation process ${ }^{15}$. The structure of chitosan is similar to glycosaminoglycans (GAGs) in mammals which mostly can be found on the cell surface and matrix extracellular ${ }^{16}$. Chitosan on the surface of materials will support cell attachment and proliferation 17,18. Chitosan has potential benefits for tissue regeneration due to its biocompatibility, biodegradability and bio-absorbability. It also increases the production of transforming-beta 1 (TGF 1) and platelet-derived growth factor (PDGF) ${ }^{19}$.

The aim of this research is to improve the characteristics of PLLA using chitosan and collagen. Collagen is the main component of the extracellular matrix that will enhance the cell adhesion and also increase elasticity ${ }^{20}$. Collagen also has a role in promoting the formation of endothelial cell ${ }^{21}$. Collagen has a good tensile strength that play an important role in the component for ligament, tendon, and it is also responsible for skin elasticity. The degradation rate of collagen can be controlled using enzymatic pre-treatment or crosslinking.

\section{METHOD}

This study was an experimental study that aimed to assess the effect of chitosan addition on the PLLA-collagen hollow fiber surface. It consisted of two steps; preparation of hollow fiber and biological properties assessment. The biological assessment of this study that had been evaluated was the cytotoxicity and hemocompatibility of materials. Cytotoxicity evaluation had been done by using MTT assay and hemolytic test for hemocompatibility evaluation. The independent variable of this research was chitosan concentration, while the dependent variables were living cell viability and hemolytic percentage.

\section{Preparation of Hollow Fiber}

Hollow fiber was made from PLLA (Mw 180kDa) and collagen. $20 \%$ PLLA solution was produced by dissolving PLLA with chloroform-toluene with a ratio of 5:1. PLLA solution was blended with a $1 \%$ collagen solution with a ratio of $2: 1$ using magnetic stirrer at room temperature. It was formed into hollow fiber using a spinneret apparatus (figure 1). Alcohol was used as a coagulant.

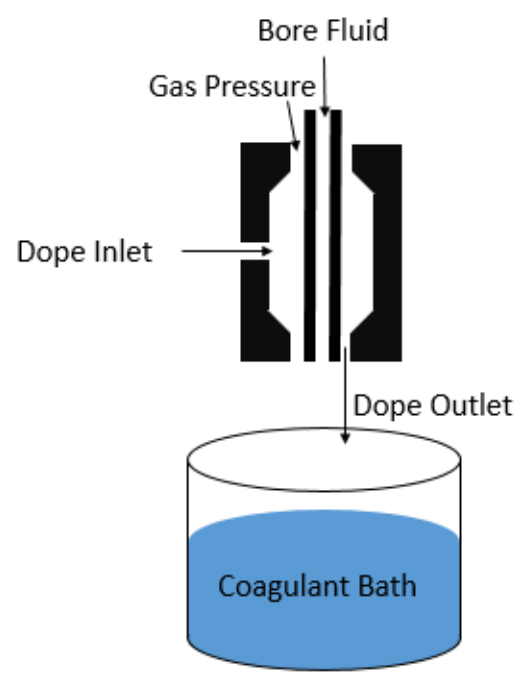

Figure 1. Spinneret apparatus scheme

The next process was coating hollow fiber with chitosan. Chitosan was dissolved on $1 \%$ acetate acid and added $1 \mathrm{~N}$ $\mathrm{NaOH}$ until $\mathrm{pH}$ reach level 6 . There were five chitosan concentration used in this research, $0.05 \% ; 0.075 \%$; $0.1 \%$; $0.125 \%$ and $0.15 \%$ (wt/v). Hollow fiber was dipped into the chitosan solution for 30 minutes. The last process of the coated hollow fiber was freeze-dried. There was one PLLA-collagen hollow fiber without chitosan coating as a control.

\section{Cytotoxicity Test}

The cytotoxicity test is a mandatory test for biomaterials. MTT assay was used in this study to assess the cytotoxicity characteristics of the hollow fiber. The confluent BHK21 cell culture from the cell line was harvested by using a $0.25 \%$ trypsin versene solution. Afterward, those cells were moved to a 96-microwell plate. The sterilized samples were put into well plates. Those well plates were incubated for 4 hours with the temperature at $37^{\circ} \mathrm{C}$. The next step was removing samples from the well plates and add $50 \mu \mathrm{L}$ on each well. In the end, the optical density of formazan crystals on a96-microwell plate was monitored by ELISA reader with $630 \lambda^{22}$. The living cells percentage can be known by the following equation:

$$
\% \text { LivingCell }=\frac{O D_{\text {treatment }}+O D_{\text {media }}}{O D_{\text {cell }}+O D_{\text {media }}} \times 100 \%
$$

\section{Hemolytic Test}

The hemolytic test is a mandatory test for biomaterials that have contact with blood. This test was using anticoagulated human blood. $200 \mu \mathrm{L}$ blood was diluted on $10 \mathrm{~mL}$ of 
$0.9 \%$ saline as a negative control, and $200 \mu \mathrm{L}$ blood was diluted on $10 \mathrm{~mL}$ aquades as a positive control. Samples were put into microtube with $200 \mu \mathrm{L}$ of blood-saline and incubated for 2 hours on the water bath with the temperature at $37^{\circ} \mathrm{C}$. Afterward, samples were removed, and the blood was centrifuged with 3000 rpm for 10 minutes. The supernatant was taken from microtube to assess the absorbance using UV-Vis spectrophotometry with $490 \mathrm{~nm}$ of wavelength. This absorbance can be used to calculate the hemolytic percentage by using following equation ${ }^{23}$ :

$$
\% \text { Hemolytic }=\frac{A_{\text {sample }}-A_{\text {negative control }}}{A_{\text {positive control }}} \times 100 \%
$$

\section{RESULTS}

Hollow fiber was successfully formed by the mixture of PLLA-Collagen using the spinneret apparatus (figure 2.a). This hollow fiber has a smooth white surface with a diameter of around 2.225-2.955 mm. The thickness of the vascular graft was also measured using the scanning electron microscope (SEM). The result showed that the thickness was between 90.65 - 236.26 $\mu \mathrm{m}$ (figure 2.b).

Cytotoxicity of the vascular graft with different concentrations of chitosan coating was evaluated on the BHK-21 cell culture. The optical density (OD) of formazan crystal and cell viability can be seen in table 1 . The percentage of the living cell for all groups was more than $50 \%$.
The hemolytic test showed that hemolytic percentage from all groups was under $5 \%$. It meant that all of the vascular graft was safe to have contact with blood ${ }^{24}$. The highest hemolytic percentage was sample 1 , and the lowest was sample 5. The percentage of hemolytic was getting smaller along with the increase of chitosan concentration.

\section{DISCUSSION}

This research had successfully produced the PLLA-collagen hollow fiber using a spinneret apparatus. This hollow fiber was coated with chitosan in order to improve the biological characteristics, cytotoxicity, and hemocompatibility. The physical of hollow fiber was observed using SEM. From the observation, it can be seen that hollow fiber has a diameter of around $2.225-2.955 \mathrm{~mm}$. Based on the diameters, this vascular graft is suitable for artery coronary application as artery coronary has a diameter of around 2.1$6.5 \mathrm{~mm}^{25}$. The pore sizes of hollow fiber also vary between $4.525-18.06 \mu \mathrm{m}$. The porosity on hollow fiber is affected by the composition of the solution, hydrogen bond, and temperature ${ }^{26}$. The increase of chitosan concentration would fill the macro-porous on PLLA with low density. Pore size has a pivotal role in the vascular graft. It is able to affect cell adhesion, which is as a key role in vascularization ${ }^{27}$. The best size of pore on vascular graft is $5-45 \mu \mathrm{m}$. By this size, the endothelial cell could grow better ${ }^{28}$.

Table 1. The result of cytotoxicity test

\begin{tabular}{lcc}
\hline Group & Optical Density Value & Cell Viability (\%) \\
\hline Control & $0.383 \pm 0.027$ & $96.03 \%$ \\
Sample 1 & $0.344 \pm 0.025$ & $88.10 \%$ \\
Sample 2 & $0.361 \pm 0.047$ & $91.56 \%$ \\
Sample 3 & $0.387 \pm 0.012$ & $96.85 \%$ \\
Sample 4 & $0.342 \pm 0.037$ & $87.69 \%$ \\
Sample 5 & $0.329 \pm 0.042$ & $85.05 \%$ \\
\hline
\end{tabular}

Table 2. The result of hemolytic test

\begin{tabular}{lcc}
\hline Group & Absorbance Average & Hemolytic Percentage (\%) \\
\hline Control & $0.0503+0.004$ & $4.24 \%$ \\
Sample 1 & $0.0453+0.003$ & $3.29 \%$ \\
Sample 2 & $0.0447+0.002$ & $3.15 \%$ \\
Sample 3 & $0.0420+0.001$ & $2.61 \%$ \\
Sample 4 & $0.0413+0.002$ & $2.45 \%$ \\
Sample 5 & $0.0380+0.001$ & $1.57 \%$
\end{tabular}

Control : PLLA-collagen hollow fiber without chitosan coating Sample 1 : PLLA-collagen hollow fiber with $0.05 \%(\mathrm{wt} / \mathrm{v})$ chitosan Sample 2 : PLLA-collagen hollow fiber with $0.075 \%$ (wt/v) chitosan
Sample 4 : PLLA-collagen hollow fiber with $0.125 \%$ (wt/v) chitosan 
Sample 3 : PLLA-collagen hollow fiber with $0.1 \%(w t / v)$ chitosan

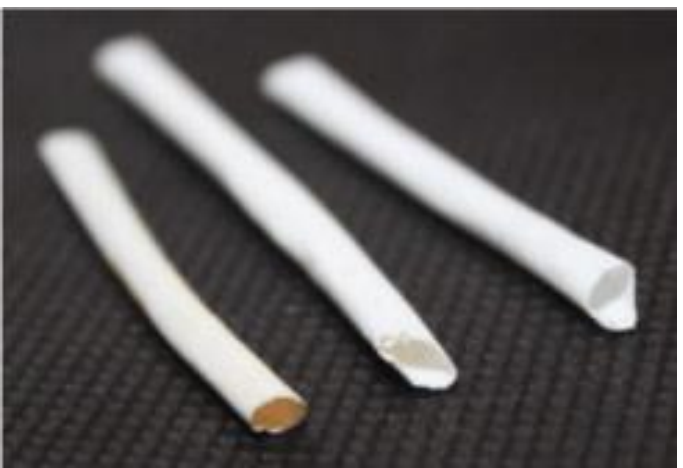

(a)
Sample 5 : PLLA-collagen hollow fiber with

$0.15 \%(\mathrm{wt} / \mathrm{v})$ chitosan

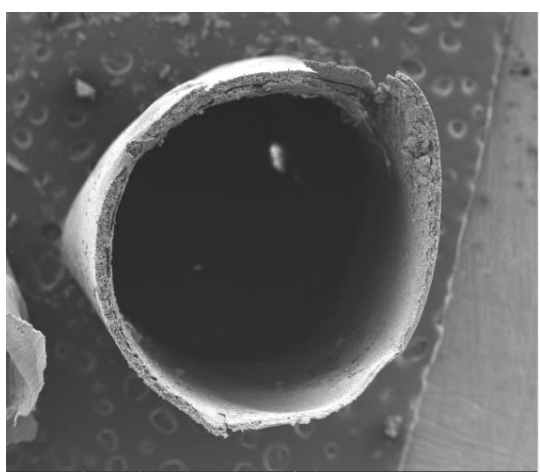

(b)

Figure 2. Hollow fiber PLLA-Collagen (a), Cross section of hollow fiber PLLA-Collagen from Scanning Electron Microscope (SEM) with 80 magnitude (b).

The cytotoxicity assay showed that the percentage of a living cell from all samples was above $50 \%$. It meant that the vascular graft from all groups is non-toxic. High optical density value indicates high cell viability in the case of MTT Assay. This OD shows the concentration of formazan crystal. Living cells absorbed MTT and broke it down through reduction reaction using reductase enzyme on mitochondria respiration chain ${ }^{29}$. The addition of chitosan did not affect the PLLA cytotoxicity.

Hemocompatibility is one of the crucial characteristics of blood contacted materials. In this research, hemocompatibility properties were measured using the hemolytic test. Hemolytic is a condition where erythrocytes were damaged due to the disruption of membrane cell integrity. The principle of the hemolytic test measures the hemoglobin level due to the destruction of red blood cells when contact with foreign materials ${ }^{30}$. Based on the hemolytic test result, all of the samples have good hemocompatibility. The hemolytic percentage showed the amount of hemoglobin due to the rupturing of erythrocyte since its contact with foreign materials. Based on ASTM F756-00, materials that are safe to contact with blood should have hemolytic percentages under $5 \%{ }^{24}$.

The increase of chitosan concentration gave a positive impact on PLLA-collagen hollow fiber. The increase in chitosan concentration decreased the hemolytic percentage. It showed that the increase in chitosan concentration could cover the PLLA-collagen surface. Chitosan made the surface of hollow fiber smoother. Therefore, it decreased the friction between the hollow fiber surface and the blood component. In the case of a vascular graft, the roughness of surface could trigger blood flow turbulence and initiate the hemolytic process ${ }^{31}$.

\section{CONCLUSIONS AND RECOMMENDATION}

The surface modification of PLLA-collagen using chitosan successfully improved its biological characteristics, especially on hemocompatibility. The increase in chitosan concentration could minimize the hemolytic process. It could be concluded that chitosan was able to enhance the hemocompatibility of the materials, which is pivotal for vascular graft candidates. Further research is still needed to evaluate the effect of chitosan concentration on the endothelialization process.

\section{REFERENCES}

1. Roth GA, Johnson C, Abajobir A, et al. Global, Regional, and National Burden of Cardiovascular Diseases for 10 Causes, 1990 to 2015. J Am Coll Cardiol. 2017;70(1).

2. Organization WH. Cardiovascular Diseases. https://www.who.int/health-topics/cardiovasculardiseases/.

3. Emelia J. Benjamin, Virani CSS, Callaway CW, et al. Heart Disease and Stroke Statistics-2018 Update: A Report From the American Heart Association. Am Hear Assoc J. 2018;137.

4. Bentzon JF, Otsuka $F$, Virmani $R$, Falk $E$. Mechanisms of Plaque Formation and Rupture. Circ Res. 2014. doi:10.1161/CIRCRESAHA.114.302721

5. Murashita T. The Choice of Graft Conduits in Coronary Artery Bypass Grafting.; 2017. doi:10.5772/intechopen.70398

6. Carrabba M, Madeddu P. Current Strategies for the Manufacture of Small Size Tissue Engineering Vascular Grafts. Front Bioeng Biotechnol. 2018;6(41). doi:10.3389/fbioe.2018.00041

7. Pashneh-Tala S, MacNeil S, Claeyssens F. The Tissue-Engineered Vascular Graft-Past, Present, 
and Future. Tissue Eng Part B Rev. 2016;22(1):68100. doi:10.1089/ten.teb.2015.0100

8. Matsuzaki Y, John K, Shoji T, Shinoka T. The Evolution of Tissue Engineered Vascular Graft Technologies: From Preclinical Trials to Advancing Patient Care. Appl Sci. 2019;9(7). doi:10.3390/app9071274

9. Hu J, Su X, Ma H, Xie C, Chen E, Ma PX. Porous nanofibrous PLLA scaffolds for vascular tissue engineering. Biomaterials. 2010;31(31):79717977. doi:10.1016/j.biomaterials.2010.07.028

10. Tara S, Rocco KA, Hibino N, et al. Vessel Bioengineering- Development of Small-Diameter Arterial Grafts -. Circ J. 2014;78:12-19. doi:10.1253/circj.CJ-13-1440

11. Schofer MD, Boudriot U, Leifeld I, et al. Characterization of a PLLA-Collagen I Blend Nanofiber Scaffold with Respect to Growth and Osteogenic Differentiation of Human Mesenchymal Stem Cells. Sci World J. 2009;9:118-129. doi:10.1100/tsw.2009.13

12. Casalini T, Rossi F, Santoro M, Perale G. Structural Characterization of Poly-L-lactic Acid (PLLA) and Poly (glycolic acid) (PGA) Oligomers. Int J Mol Sci. 2011;12:3857-3870. doi:10.3390/ijms12063857

13. Ferdous J, Kolachalama VB, Shazly T. Acta Biomaterialia Impact of polymer structure and composition on fully resorbable endovascular scaffold performance. Acta Biomater. 2013;9(4):6052-6061.

doi:10.1016/j.actbio.2012.12.011

14. Ma Z, Gao C, Gong Y, Ji J, Shen J. Immobilization of Natural Macromolecules on Poly-L-Lactic Acid Membrane Surface in Order to Improve Its Cytocompatibility. 2002;(January):838-847. doi:10.1002/jbm.10470

15. M. P, Rodriguez-Perez MA, Saja JA de, Mano JF. Preparation and Characterization of Poly(L-Lactic Acid)- Chitosan Hybrid Scaffolds with Drug Release Capability. J Biomed Mater Res Part B Appl Biomater. 2006;81B(2). https://doi.org/10.1002/jbm.b.30680.

16. J. Griffon D, Sedighi MR, V. Schaeffer D, Eurell JA, Johnson AL. Chitosan scaffolds: Interconnective pore size and cartilage engineering. Acta Biomater. 6AD;2(3):313-320.

doi:10.1016/j.actbio.2005.12.007

17. Lee JE, Kim SE, Kwon IC, et al. Effects of a Chitosan Scaffold Containing TGF- $\beta 1$ Encapsulated Chitosan Microspheres on In Vitro Chondrocyte Culture. Artif Organs. 2004;28(9). doi:10.1111/j.1525-1594.2004.00020.x

18. Bumgardner JD, Wiser R, Elder SH, Jouett R, Yang $\mathrm{Y}$, Ong JL. Contact angle, protein adsorption and osteoblast precursor cell attachment to chitosan coatings bonded to titanium. J Biomater Sci Polym Ed. doi:10.1163/156856203322599734

19. Uenoa H, Nakamura F, Murakami M, Okumura M, Kadosawa T, Fujinaga T. Evaluation effects of chitosan for the extracellular matrix production by fibroblasts and the growth factors production by macrophages. Biomaterials. 2001;22(15):21252130. doi:10.1016/S0142-9612(00)00401-4

20. Inoue N, Sugihara F, Wang $X$. Ingestion of bioactive collagen hydrolysates enhance facial skin moisture and elasticity and reduce facial ageing signs in a randomised double-blind placebocontrolled clinical study. $J$ Sci Food Agric. 2016;96(12). doi:10.1002/jsfa.7606

21. Ardila DC, Liou J-J, Maestas D, et al. Surface Modification of Electrospun Scaffolds for Endothelialization of Tissue-Engineered Vascular Grafts Using Human Cord Blood-Derived Endothelial Cells. J Clin Med. 2019;8(2). doi:10.3390/jcm8020185

22. Sularsih, Soetjipto, Rahayu RP. Cytotoxicity of Combination Chitosan with Different Molecular Weight and Ethanol Extracted Aloe vera using MTT Assay. IOP Conf Ser Earth Environ Sci. 2018;217(1). doi:10.1088/17551315/217/1/012030

23. Belanger MC, Marois $\mathrm{Y}$, Roy R, et al. Selection of a polyurethane membrane for the manufacture of ventricles for a totally implantable artificial heart: Blood compatibility and biocompatibility studies. Artif Organs. 2000;24(11):879-888. doi:10.1046/j.1525-1594.2000.06504.x

24. Hendershot MD, Corvo MF, Vistoft-Nielsen SL, et al. ASTM Hemolysis.; 2007. http://www.modernplastics.com/wpcontent/pdf/hemolysis.pdf.

25. Ajayi NO, Lazarus L, Vanker EA, Satyapal KS. Anatomic Parameters of the Left Coronary Artery: an Angiographic Study in a South African Population. Int J Morphol. 2013;31(4):1393-1398. doi:10.4067/S0717-95022013000400039

26. Widjojo N, Chung T. Thickness and Air Gap Dependence of Macrovoid Evolution in PhaseInversion Asymmetric Hollow Fiber Membranes. Ind Eng Chem Res. 2006;45(22):7618-7626. doi:10.1021/ie0606587

27. K. SA, R. S, G. PR, et al. Interactions of $3 T 3$ fibroblasts and endothelial cells with defined pore features. J Biomed Mater Res. 2002;61(2):212217. doi:10.1002/jbm.10195

28. Narayan D, Venkatraman SS. Effect of pore size and interpore distance on endothelial cell growth on polymers. J Biomed Mater Res - Part A. 2008;87(3):710-718. doi:10.1002/jbm.a.31749

29. Riss TL, Moravec RA, Niles AL, et al. Cell Viability Assays.; 2016.

30. Vijayanand K, Pattanayak DK, Mohan TRR, Banerjee R. Interpreting Blood-Biomaterial Interactions from Surface Free Energy and Work of Adhesion. Trends Biomater Artif Organs. 2005;18(2).

31. Umezu M, Yamada T, Fujimasu H, et al. Effects of surface roughness on mechanical hemolysis. Artif Organs. 1996;20(6):575-578. doi:10.1111/j.15251594.1996.tb04484.x 